\title{
Síndrome de Piel Escaldada. Avances en Diagnóstico y Tratamiento
}

\author{
(Scalded Skin Syndrome. Advances in Diagnosis and Treatment)
}

\author{
Nicolás Faúndes Gandolfo ${ }^{1 *}$, Sebastián Estrada Eguiguren', \\ Alonso García Valdebenito ${ }^{1}$, Javiera Leiva Mora ${ }^{1}$, \\ Karen Ducasse Crespo ${ }^{2,3}$
}

\begin{abstract}
${ }^{1}$ Internos de Medicina, Universidad de Valparaíso, Chile ${ }^{2}$ Infectóloga Pediatra, Hospital Dr. Gustavo Fricke, Viña del Mar, Chile ${ }^{3}$ Docente Departamento de Pediatría, Universidad de Valparaíso, Chile

*Autor para correspondencia: nicolas.faundes@gmail.com

RECIBIDO: 09 de Noviembre de 2019 APROBADO: 21 de Noviembre de 2019
\end{abstract}

DOI: 10.22370/bolmicol.2019.34.2.2004

LOS AUTORES DECLARAN NO TENER CONFLICTO DE INTERESES

Palabras claves: Síndrome de piel escaldada estafilocócico, Síndrome de shock tóxico estafilocócico, Infección por Staphylococcus aureus.

Key words: Staphylococcal scalded skin syndrome, Staphylococcal toxic shock syndrome, Staphylococcus aureus infection.

\section{RESUMEN}

Síndrome de piel escaldada estafilocócica (SSSS, por sus siglas en inglés) es una entidad clínica generada por toxinas epidermolíticas producidas por el microorganismo Staphylococcus aureus que destruye las uniones celulares de la epidermis. Esta afectación produce un compromiso cutáneo caracterizado por exfoliación superficial de la piel, celulitis eritematosa y bulas que se pueden expandir hacia gran parte del cuerpo. Esta enfermedad se describe como una infección mediada por toxinas que afecta principalmente pacientes pediátricos y algunos adultos. Las medidas terapéuticas más importantes para disminuir la tasa de mortalidad son el tratamiento de soporte con analgesia, cuidado de heridas y tratamiento antibiótico con antiestafilocócicos. Se recomienda enfrentar esta enfermedad con un enfoque multidisciplinario debido a los diagnósticos diferenciales que incluyen manifestaciones de reacción adversas a medicamentos, necrólisis epidérmica tóxica o síndrome de Steven Johnson por lo que requiere la evaluación por al menos dermatólogos, infectólogos y cirujanos. El propósito de esta revisión es resumir las bases clínicas, etiopatogénicas, complicaciones, tratamiento actual según evidencia y proyecciones a futuro.

\section{ABSTRACT}

Staphylococcal scalded skin syndrome (SSSS) is a clinical entity generated by epidermolytic toxins produced by the microorganism Sta- 
phylococcus aureus which destroys the cellular junctions of the epidermis. This affectation produces a cutaneous compromise characterized by superficial skin exfoliation, erythematous cellulitis and blisters that can expand to a large part of the body. This disease is described as an opportunistic infection toxin-mediated which primarily affects pediatric patients and some adults. The most important therapeutic measures to reduce the mortality rate are supportive treatment with analgesia, wound care and parenteral anti-staphylococcal antibiotics. It is recommended to face this disease with a multidisciplinary approach due to differential diagnoses that include manifestations of adverse drug reactions, toxic epidermal necrolysis or Steven Johnson's syndrome, so it requires evaluation by at least dermatologists, infectologists and surgeons. The purpose of this review is to summarize the clinical, etiopathogenic bases, complications, current treatment according to evidence and future projections.

\section{INTRODUCCION}

El síndrome de piel escaldada estafilocócica (SSSS), descrito por primera vez por un médico alemán Baron Gotfried Ritter von Rittershain en 1878. Corresponde a una dermatosis aguda causada por las toxinas epidermolíticas A y B del Staphylococcus aureus, y que se presenta clínicamente con fiebre, eritema y desprendimientos epidérmicos generalizados(1).

El género Staphylococcus contiene más de 32 especies y subespecies, de las que sólo unas pocas son patógenas. $S$. aureus es la especie más virulenta del género Staphylococcus y constituye una causa frecuente de morbi-mortalidad en la actualidad, a pesar del desarrollo antimicrobiano. Produce infecciones tanto invasoras como por toxinas -entre las que se encuentra el SSSS- y tienen un comportamiento oportunista con tendencia a producir abscesos y metástasis sépticas(2).
Alrededor del $25-50 \%$ de las personas sanas están colonizadas de forma transitoria o permanente por este microorganismo, y este porcentaje es aún mayor en pacientes diabéticos dependientes de insulina, con infección por el virus de la inmuno- deficiencia humana (VIH), con insuficiencia renal en programa de diálisis, usuarios de drogas por vía parenteral y con dermopatías crónicas. Los sitios más frecuentes de colonización son las fosas nasales, las axilas, el periné, la vagina y la orofaringe. Estos lugares son los reservorios de las futuras infecciones, por lo que éstas son más frecuentes en pacientes colonizados previamente(3).

Se describe una prevalencia entre $0.09 \mathrm{y}$ 0.56 personas por cada 1.000 .000 de habitantes, con una relación entre hombres y mujeres de $2: 1$, siendo más frecuente en recién nacidos (adquisición por vía canal de parto) y pacientes menores de 5 años. El pico de edad de presentación es entre los 2 y 3 años(4).

Dentro de los factores de riesgo de SSSS se describen la inmadurez renal, la insuficiencia renal crónica, inmunodepresión y el déficit de inmunoglobulinas(5).

Por otra parte, el SSSS presenta una alta morbimortalidad si es que no es tratado rápida y adecuadamente. En adultos se han informado tasas de mortalidad de hasta el $60 \%$ probablemente explicada por su expresión subyacente a patologías severas o estados de inmunodepresión. En niños la mortalidad es generalmente más baja no superando el 5\%(6).

\section{Patogenia}

La colonización por $S$. aureus se encuentra en aumento, junto con ellos la por los meticilinoresistentes, los cuales están cada vez generando más complicaciones, entre ellas el SSSS. A pesar de lo anterior, sólo un 5\% de los $S$. aureus aislados en humanos producen las toxinas exfoliativas 
A (ETA) y B (ETB). Éstas últimas son proteínas séricas atípicas tripsinas-like, ácido glutámico específico que se acumulan en la piel, siendo descrita ETB como la más agresiva de las dos(5).

A medida que ETA y ETB se acumulan en la piel, generan la escisión del complejo de desmogleína 1, una cadherina desmosomal involucrada en la adhesión celular de los queratinocitos. La desintegración de los desmosomas que anclan los estratos granulosos, es lo que finalmente causa la exfoliación. El Staphylococcus que inicialmente causa la enfermedad a menudo no se encuentra en las biopsias o cultivos, pues la toxina es capaz de viajar por el torrente sanguíneo afectando lugares lejanos al sitio de infección primaria, pero que generalmente se origina en la zona de cabeza y cuello (conjuntivitis, rinofaringitis, otitis media)(6).

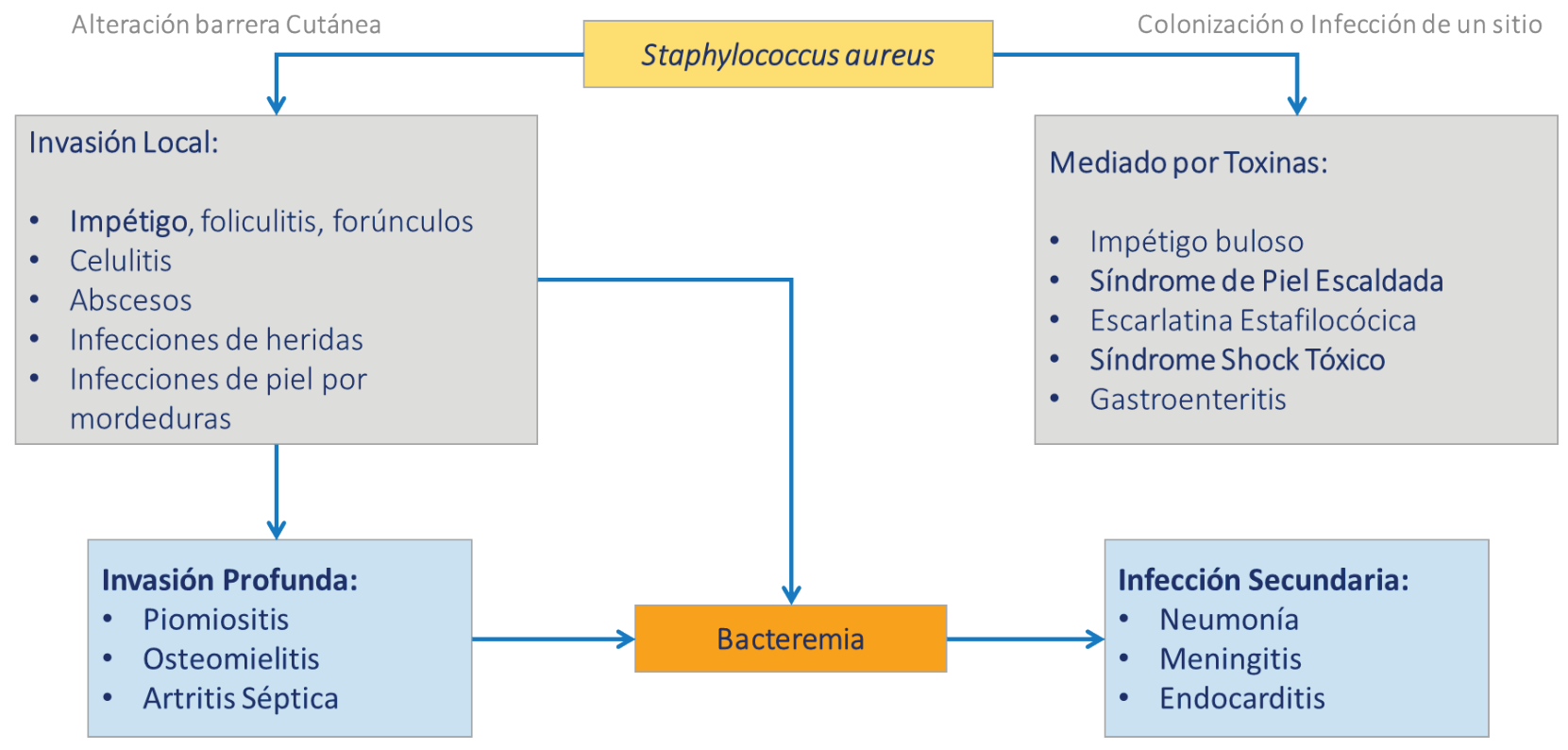

Figura 1. Mecanismos patogénicos S. aureus.

\section{Factores de riesgo}

Es una patología que puede ocurrir a cualquier edad, pero como ha sido mencionado es más común en niños menores de 5 años, sin diferencia entre sexos tanto en niños como adultos. Se ha descrito también un aumento en la incidencia en niños durante verano y otoño(5).

La mayor prevalencia en niños se ha tratado de explicar por diversas teorías, una de ellas la ausencia de desarrollo de anticuerpos protectores contra las toxinas exfoliativas y la otra la inmadurez de los riñones para su excreción(5). En el caso de los adultos, el mayor factor de riesgo es la presencia de enfermedades subyacentes, princi- palmente renales (con mortalidad mayor al $60 \%$ ), inmunodepresión, asociada a insuficiencia renal, diabetes mellitus, neoplasias malignas, quimioterapia, uso de drogas endovenosas o infección por el virus de la inmunodeficiencia humana. Los mecanismo implicados en la patogenia asociados a estos factores de riesgo sería una dificultad en la excreción de la toxina como de la producción de anticuerpos contra ella(5).

Por otra parte los pacientes usuarios de hemodiálisis poseen riesgo mayor de infección por la presencia de accesos vasculares infectados, la incapacidad de excreción renal y el déficit inmunológico que lo acompaña. (7) 
Los casos de adultos inmunocompetentes con la enfermedad se han visto asociados a la cepa de $S$. aureus portadora de un gen que codifica la exotoxina ETB, más virulenta. (8)

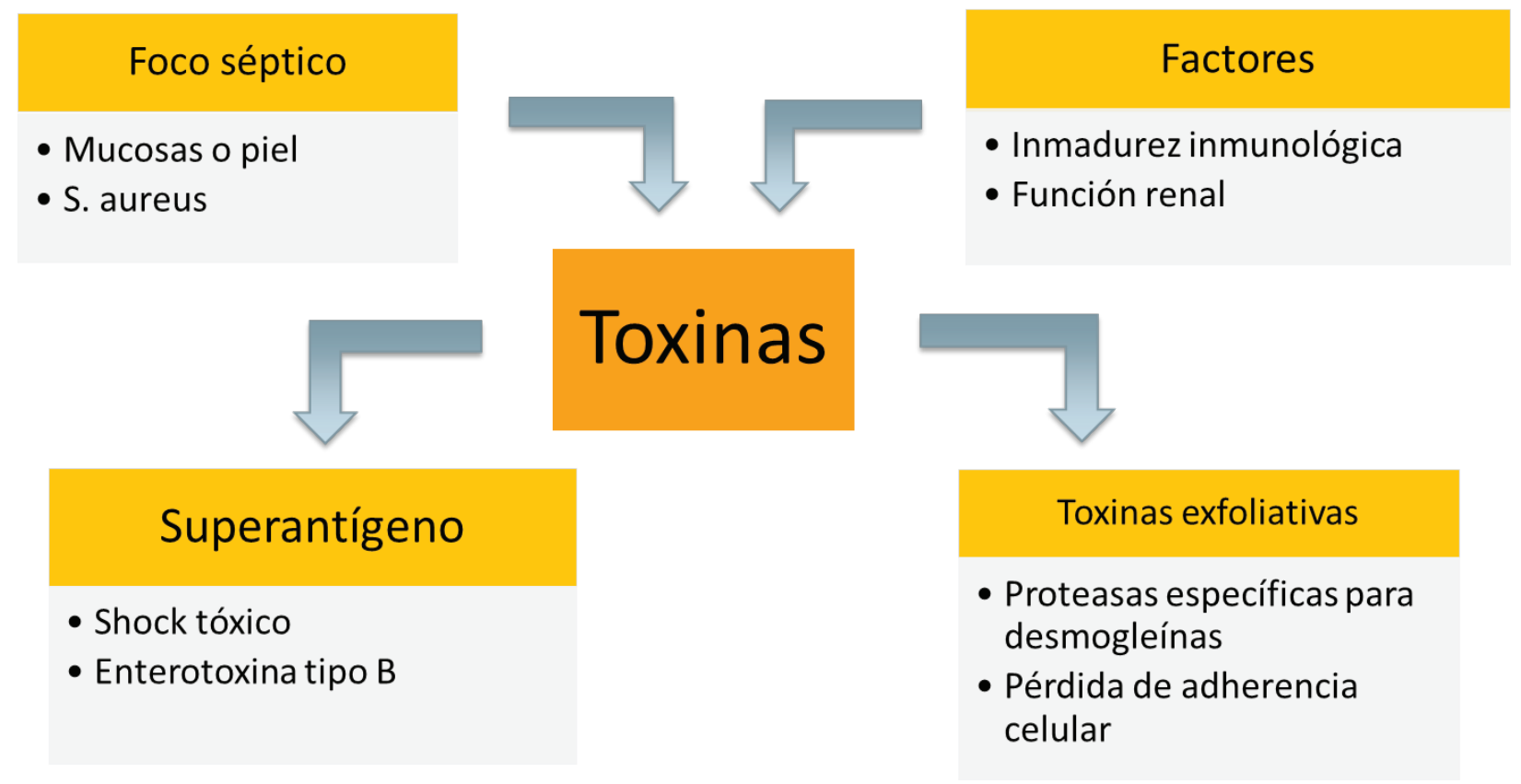

Figura 2. Mecanismos Fisiopatológicos SSSS. (Adaptada Mishra, AK et al. 2016).

\section{Cuadro clínico}

El tiempo de incubación varía entre 1 a 10 días desde la infección, hasta la posible expresión de un SSSS. El cuadro clínico de forma clásica inicia con pródromo caracterizado por malestar general, fiebre, seguido de un exantema eritematoso generalizado que inicia de forma abrupta. Al segundo día evoluciona con exantema escarlatiniforme, hiperestesia cutánea con lesiones ampollosas con signo de Nikolski positivo (ruptura fácil de la bula frente a presión tangencial suave) en tronco, pliegues, región periorificial, sitios desde donde las lesiones se esparcen. Entre el tercer y quinto día evolucionan a una exfoliación cutánea generalizada, dando paso a parches eritematosos bien definidos, que pueden extenderse en áreas mayores a las lesiones iniciales, normalmente acompañada de fiebre y alteración de la consciencia(9). Las áreas de piel denudada son sitios de pérdida de líquido seroso, que suelen ser áreas de fácil infección secundaria. Los niños suelen tener una se- gunda etapa de descamación aproximadamente 10 días después. Las lesiones presentan cicatrización ad integrum en 14 días, sin secuelas cutáneas. La presentación clínica en adultos es similar a la de los niños, sólo que con un curso que suele ser más severo(5).

En caso de recién nacidos ocurre entre el tercer y séptimo día de vida, con sólo un caso reportado de SSSS congénito. No presenta afectación de mucosas a diferencia del síndrome de Lyell o necrólisis epidérmica tóxica. Es un cuadro autolimitado de 4-7 días, donde además en las lesiones no se encuentra nunca la bacteria. Estas lesiones además pueden estar en conjunto con un impétigo buloso(10).

\section{Diagnóstico}

El diagnóstico es principalmente clínico. La sospecha se da frente a expresión de lesiones vesículo-bulosas, con signo de Nikolsky positivo y 
apariencia de piel escaldada. Inicialmente el SSSS puede asimilarse a otros trastornos como la necrólisis epidérmica tóxica, reacción inmunológica a fármacos o infección, las cuales son clínicamente diferenciables por la ausencia de afección de mucosas, la descamación más superficial del SSSS y la ausencia del antecedente del fármaco(1).

Se pueden realizar hemocultivos, dónde es probable aislar el microorganismo pero cuyo rendimiento es bajo. Los cultivos de las lesiones no están recomendados. La realización de PCR para el gen de la toxina exfoliativa no es necesaria para el diagnóstico más allá de fines académicos (11) dado que no se encuentra disponible en nuestros servicios.

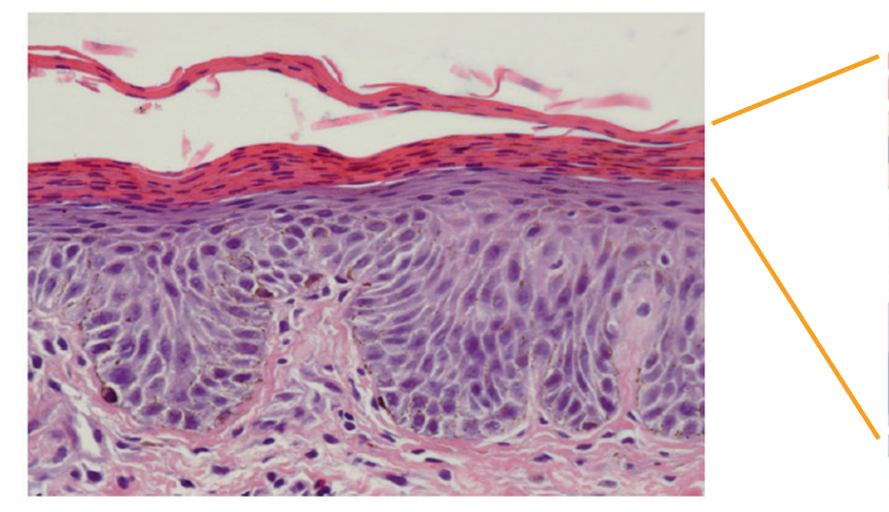

Exámenes histológicos pueden rápidamente diferenciar el SSSS de otras patologías semejantes, para ello es recomendado una biopsia, la cual tampoco es estrictamente necesaria para el diagnóstico(1).

\section{Histología}

La biopsia de piel puede establecer el diagnóstico de SSSS, mostrando una escisión intraepidérmica superficial por debajo del estrato córneo, sin inflamación, sin queratinocitos necróticos. La clave de la diferenciación histológica es el nivel al cual la escisión ocurre, en SSSS es mucho más superficial que en otras patologías como necrólisis epidérmica tóxica, por ejemplo(12).

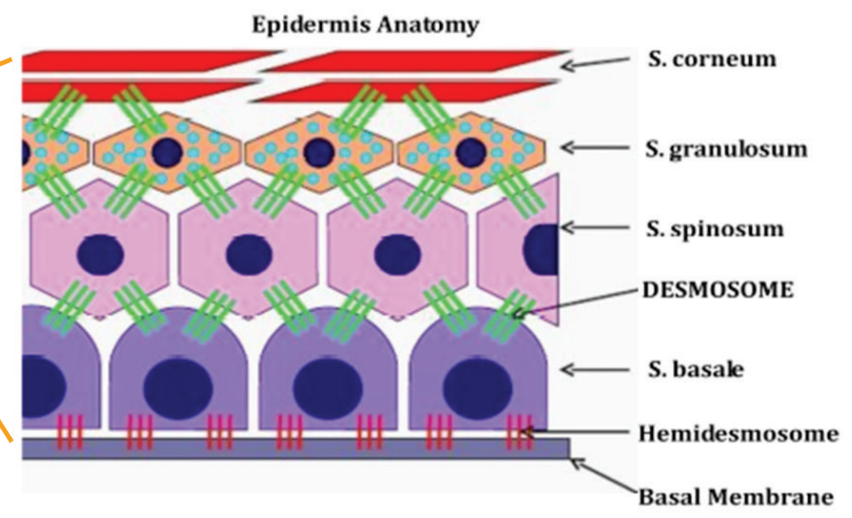

Figura 3. Biopsia y representación histopatológica del SSSS (Adaptada Mishra, AK et al. 2016 y Handler, MZ et al. 2014).

\section{Complicaciones}

Las complicaciones del SSSS incluyen neumonía, deshidratación, síndrome de shock tóxico y sepsis, aunque son poco frecuentes(5). La deshidratación puede conducir a desequilibrios electrolíticos; por lo tanto, el manejo de fluidos y el monitoreo de laboratorio son clave. El diagnóstico y el tratamiento oportunos detienen la exfoliación adicional y previenen la morbilidad y la mortalidad(6).

\section{$\underline{\text { Tratamiento }}$}

Requiere un enfoque combinado, siendo el mejor lugar de estadía una unidad de paciente crítico o quemado. Se puede dividir en 3 pilares fundamentales: Soporte, analgesia y antibiotera$\operatorname{pia}(13)$.

\section{Soporte}

Los pacientes necesitan cuidados similares a los de quemaduras térmicas, con reposición de fluidos, y cuidados de heridas (14). Se debe compensar la pérdida de fluidos y prevenir hipovolemia, se debe controlar regularmente los electrolitos y poner especialmente atención a hiponatremia por hipervolemización(5). Para evitar 
infecciones secundarias y facilitar la recuperación se debe cubrir la piel denudada. El área denudada debería ser cubierta con apósito primario de silicona suave, cubierta por gasa empapada en solución salina (15). En adultos y niños se debe mantener en reposo utilizando frazadas de aire caliente para mantener una temperatura central de $37^{\circ} \mathrm{C}$. Además de realizar fisioterapia para mantener movilidad de las articulaciones, de esta forma reduciendo la morbilidad y favoreciendo la recuperación(13).

\section{Analgesia.}

Con paracetamol y opioides como fentanilo $(1-4 \mu \mathrm{g} / \mathrm{kg} / \mathrm{h})$ se pueden administrar según necesidad. AINEs deberían excluirse debido a que poseen excreción renal e incrementan el riesgo de sangrado (15). En pacientes pediátricos, sedación con midazolam $(50-100 \mu \mathrm{g} / \mathrm{kg} / \mathrm{h})$ puede ser beneficiosa. Para el prurito se pueden utilizar medicamentos según necesidad(5).

\section{Antibioterapia.}

Si bien el síndrome de piel escaldada continuará su progresión por 24 a 48 horas después del inicio hasta que las exotoxinas hayan sido neutralizadas por anticuerpos o excretadas por vía hepática es importante iniciar los antibióticos lo antes posible (13). El tratamiento consiste de la erradicación de la infección primaria con antibióticos antiestafilocócicos (Cloxacilina por ejemplo) administrado por vía endovenosa por un mínimo de 7 días. Actualmente se estima que todas las cepas estafilocócicas contienen penicinilasas y son resistentes a Penicilina (14). Penicilinas sintéticas como Flucloxacilina deberían administrarse inmediatamente en dosis de $50-150 \mathrm{mg} / \mathrm{kg} /$ día en niños y adultos 500-1000mg/día, ambos divididos en 4 dosis (15).

En áreas con prevalencia de $S$. aureus meticilino resistente o si se sospecha infección por $S$. aureus meticilino resistente se debe cubrir con Vancomicina (45 mg/kg/día en 3 dosis diarias) (16). La Clindamicina se reconoce como útil en infecciones estafilocócicas para neutralizar la secreción de exotoxina (17-18). Si el paciente presenta alergia a Cloxacilina se puede usar Ciprofloxacino o Cefuroxima (5).

\section{Otras terapias:}

En el caso de pacientes que no han mejorado con tratamiento antibiótico se ha planteado el uso de agentes neutralizadores de exotoxina, como plasma fresco congelado e inmunoglobulinas, pero no se han realizado estudios clínicos aleatorizados (5). Algunas de las alternativas terapéuticas son las siguientes:

- Corticoides: El uso de corticoesteroides debería disuadirse pues se ha asociado a empeoramiento de la enfermedad (19).

-Inmunoglobulinas: Inmunoglobulinas endovenosas ha sido recomendado para combatir el SSSS pero reporte de casos recientes han relacionado un aumento en la estadía hospitalaria de estos pacientes (5).

- Plasma fresco congelado: 91\% de los adultos mayores de 40 años tienen anticuerpos contra la toxina exfoliativa, niños que se encuentren en mal estado pueden recibir una dosis de plasma fresco congelado $(10 \mathrm{mg} / \mathrm{kg})$ para neutralizar los anticuerpos contra la exotoxina (20-21).

-Laxantes: Se ha teorizado el uso de agentes como lactulosa para ayudar en la excreción de toxina, sobre todo en pacientes pediátricos extremos en contexto de no poseer un riñón con función completamente desarrollada (6).

\section{Pronóstico}

La mayoría de los casos se resuelve sin secuelas entre 2 a 3 semanas luego de tratamiento efectivo (11). En el grupo de pacientes pediátricos la mortalidad es alrededor del $4 \%$ y se asocia con compromiso extenso de la piel, sepsis refractaria y desbalance hidroelectrolítico (19-22). En la población adulta, se reporta mortalidad que puede llegar hasta ser superior al $60 \%$, que se puede atribuir a condiciones subyacentes predisponentes a la enfermedad (11-19). 


\section{$\underline{\text { Diagnósticos diferenciales }}$}

\section{Síndrome de Shock Tóxico Estafilocócico}

Corresponde a una complicación poco frecuente derivado de una infección por S. aureus. Clínicamente se manifiesta por fiebre, rash cutáneo y shock que pueden progresar a compromiso multiorgánico (falla renal, hepática, CID, distrés respiratorio, etc). Es producido por la toxina TSST-1 que actúa como superantígeno generando una respuesta inmune exacerbada con gran liberación de citoquinas (23). Puede cursar con alteraciones en exámenes de laboratorio caracterizado por: leucocitosis con neutrofilia, plaquetopenia, tiempo de protrombina aumentado y leucopenia, asociado a grados variables de alteración de perfil bioquímico según el grado de compromiso multiorgánico. Un estudio complementario corresponde a la PCR de genes de TSST-1 (23-24-25).

El tratamiento posee tres pilares: la reanimación, los antibióticos y los inmunomoduladores. La reanimación inicia con la reposición con cristaloides y la monitorización con catéter venoso central. Frente al fracaso terapéutico se continúa con drogas vasopresoras (norepinefrina y dobutamina). El manejo microbiológico consiste en eliminar el posible desencadenante de la infección y tratar con antibióticos previo hemocultivo. El tratamiento antibiótico debe ser de amplio espectro incluyendo Cloxacilina o Flucoxacilina asociado a Clindamicina que logra control de la producción de toxinas TSST-1. Linezolid y Tigeciclina han demostrado tener efectos inhibitorios en la producción de toxinas siendo una alternativa de tratamiento frente a agentes resistentes. Se ha demostrado la utilidad del uso de las Inmunoglobulinas como inmunomoduladores que bloquean la acción de superantígeno de la toxina TSST-1 (23-24-25). Necrólisis Epidérmica Tóxica - Síndrome de
Stevens-Johnson

El síndrome de Stevens-Johnson (SSJ) y la Necrólisis Epidérmica Tóxica (NET) son parte de un mismo espectro de patología, consistente en una reacción de hipersensibilidad cutánea, generalmente causado por fármacos. La diferencia entre estos cuadros está dada por el porcentaje de superficie cutánea comprometida (menor a $10 \%$ en SSJ y mayor al $30 \%$ en NET). La fisiopatología es desconocida, pero se cree que estaría causado por una capacidad alterada para depurar metabolitos intermedios de fármacos, los que formarían complejos antigénicos desencadenando la respuesta inmune en el individuo afectado. Se han descrito múltiples susceptibilidades genéticas. En la mayoría de los casos es causado por fármacos, aunque también se han descrito cuadros por Mycoplasma pneumoniae, herpes, VIH, virus de hepatitis. Dentro de los medicamentos más frecuentemente relacionados se describe el alopurinol, la carbamazepina, la lamotrigina. (26-27).

Se describe una incidencia entre $0.4-1.2$ personas por millón anualmente. Puede ocurrir en cualquier grupo etario, más frecuentemente en mujeres, infectados con VIH, trasplantados de médula ósea, adultos mayores y pacientes con lupus eritematoso sistémico(26).

Generalmente inicia con un pródromo con síntomas similares a la influenza, mialgias, artralgias, compromiso de estado general y fiebre. Algunos días después, se producen lesiones cutáneas eritematosas (por ejemplo en diana), e importante destacar que alrededor del $95 \%$ de los pacientes con SSJ/NET tienen compromiso de mucosas (a diferencia del síndrome de piel escaldada donde no es algo frecuente). Posteriormente se producen zonas de desprendimiento epidérmico (signo de Nikolsky positivo)(27).

Los pilares del tratamiento son retirar el agente causal, cuidados de soporte. Como ya se mencionó anteriormente, gran parte de estos cuadros es producido por fármacos, por lo que ante un evento de estas características se debe suspender 
el supuesto medicamento causante. En caso de que el origen sea bacteriano, se debe realizar el manejo antibiótico correspondiente(26). El manejo de soporte incluye idealmente el ingreso a una unidad de cuidados intensivos o unidad de cuidado de quemados, detección y tratamiento de sobreinfección de las lesiones, equilibrio hidroelectrolítico, soporte nutricional (28). Se han descrito distintos manejos inmunomoduladores, pero su efectividad es controversial. Entre estos se mencionan corticoides, inmunoglobulinas, ciclosporina(27).

\section{Reacción Medicamentosa con Eosinofilia y Sín- tomas Sistémicos}

Otro diagnóstico diferencial del SSSS es la reacción medicamentosa con eosinofilia y síntomas sistémicos (síndrome DRESS, por sus siglas en inglés), cuadro poco frecuente que compromete piel y órganos internos. Su frecuencia se estima 1 en 1000 a 10000 exposiciones a drogas. Dentro de los medicamentos a los que se atribuye este cuadro se encuentran los anticonvulsivantes (por ejemplo, Carbamazepina), antibióticos, alopurinol (29).

La fisiopatología no es completamente comprendida. Se ha postulado un mecanismo anormal de detoxificación enzimática de metabolitos de fármacos. También se ha asociado con reactivación de virus de la familia de los herpes(30).

DRESS generalmente ocurre entre 2 a 6 semanas posterior al uso del medicamento. Comienza con un pródromo de prurito y fiebre, que antecede en varios días a las manifestaciones cutáneas. Estas son diversas, pero lo más frecuente es el rash morbiliforme. La distribución clásica involucra primero el rostro, tronco y extremidades superiores, y luego se distribuye a extremidades inferiores. Puede asociarse a vesículas, bulas, lesiones en diana y púrpura. El rash puede progresar y generar dermatitis exfoliativa. Es común que se produzca edema facial y compromiso de mucosas(30). En este síndrome los sistemas afectados con mayor frecuencia son el linfático (adenopatías), hematológico (leucocitosis, eosinofilia) y hepático (elevación de transaminasas, fosfatasas alcalinas), seguidos por el renal, pulmonar y car$\operatorname{diaco}(30)$.

Se han propuesto 3 formas de criterios diagnóstico, uno de ellos es son los criterios de Bocquet, que incluye la erupción cutánea, eosinofilia, y compromiso de algún órgano interno descrito para este síndrome(29).

La medida terapéutica más importante es identificar el fármaco causante y suspender su administración. Se debe considerar el manejo sintomático, lo que incluye antipiréticos y corticoides tópicos para aliviar síntomas cutáneos. Si evoluciona con dermatitis exfoliativa, se debe realizar manejo hidroelectrolítico, soporte nutricional, tratamiento antibiótico en caso de sobreinfección bacteriana. Para la mayoría de los pacientes se recomienda el inicio temprano de corticoides sisté$\operatorname{micos}(29-30)$.

\section{DISCUSIÓN}

El síndrome de SSSS es una dermatosis aguda causada por toxinas del S. aureus, microorganismo que coloniza de forma permanente o transitoria a una porción no despreciable de la población (3). Dado lo anterior, dentro de sus características importantes es que se considera una infección oportunista, sin embargo, el SSSS tiene una alta morbimortalidad si es que no se trata oportunamente.

Presenta una clínica descrita en numerosas publicaciones, pero requiere de alta sospecha clínica y descarte de diagnósticos diferenciales con síntomas y signos parecidos (1). Junto con lo anterior debido a su baja incidencia la mayoría de la evidencia respecto al manejo proviene de reporte de casos y opinión de expertos, pese a que incluso 
se han descritos los mecanismos etiopatogénicos implicados (13). Dado lo anterior, planteamos los siguientes desafíos a futuro.

\section{Desafíos}

- Análogos de desmogleina 1: La desmogleina-1 es una cadherina desmosomal involucrada en la adhesión intracelular encontrada solamente en la epidermis superficial (31). Amagi y cols. demostró que incubando toxina exfoliativa A con extractos de epidermis de ratón demostró que la toxina era capaz de clivar el dominio extracelu- lar de desmogleina-1 humana y de ratón en razón dosis dependiente (32). Se ha teorizado que se podrían desarrollar análogos de desmogleina-1 para inhibir la acción de las exotoxinas y de esta forma, reducir la exfoliación en el paciente. $\mathrm{Pu}$ diéndose usar para unirse y neutralizar la toxina in vivo y prevenir que ésta llegue a la epidermis. Esta terapia podría convertirse en casos de síndrome de piel escaldada estafilocócica diseminada en pacientes inmunocomprometidos (33). Sin embargo, no se han encontrado mayores avances en la literatura revisada en esta arista.

\section{REFERENCIAS}

1. Alexander K. C. Leung, Benjamin Barankin, Kin Fon Leong. Staphylococcal scalded skin syndrome: evaluation, diagnosis, and management. World Journal of Pediatrics. 2018; 14 (2), 116-120. doi:10.1007/s12519-018-0150-x.

2. Barberán, J., Menéndez Martínez, M. A., \& del Valle Navarro, M. C. Infecciones por estafilococo. Clasificación. Factores predisponentes. Aspectos patogénicos de relevancia clínica o diagnóstica. Manifestaciones clínicas. Formas de comienzo. Medicine - Programa de Formación Médica Continuada Acreditado. 2010; 10(50): 3346-3351. doi:10.1016/s0304-5412(10)70041-x

3. Chambers, HF. The changing epidemiology of Staphylococcus aureus?. Emerg Infect Dis. 2001;7(2):178-182.

4. Arenas R. Dermatología: atlas, diagnóstico y tratamiento. 6e: Mcgraw-Hill Interamericana Editores, 2015.

5. Handler MZ, Schwartz RA. Staphylococcal scalded skin syndrome: diagnosis and management in children and adults. J Eur Acad Dermatol Venereol. 2014; 28(11): 1418-23.

6. Haasnoot, P. J., \& De Vries, A. Staphylococcal scalded skin syndrome in a 4-year-old child: a case report. Journal of Medical Case Reports. 2018; 12(1). doi:10.1186/s13256-017-1533-7

7. Borchers SL, Gomez EC, Isseroff R. Generalized staphylococcal scalded skin syndrome in an anephric boy undergoing hemodialysis. Arch Dermatol. 1984; 120: 912-918.

8. Stevens LA, Viswanathan G, Weiner DE. CKD and ESRD in the elderly: current prevalence, future projections, and clinical significance. Adv Chronic Kidney Dis. 2010; 17: 293-301.

9. Silva V Sergio, Valdés F Roberto, Vera K Cristián. Caso clínico dermatológico. Rev. chil. pediatr. 2004; 75(4): 367-371.

10. Ladhani, S., Joannou, C. L., Lochrie, D. P., Evans, R. W., \& Poston, S. M. Clinical, Microbial, and Biochemical Aspects of the Exfoliative Toxins Causing Staphylococcal Scalded-Skin Syndrome. Clinical Microbiology Reviews. 1999; 12(2), 224-242. doi:10.1128/cmr.12.2.224).

11. Berk DR, Bayliss SJ. MRSA, staphylococcal scalded skin syndrome, and other cutaneous bacterial emergencies. Pediatr Ann. 2010;39: 627-33.

12. Abate, M. S., Battle, L. R., Emerson, A. N., Gardner, J. M., \& Shalin, S. C. Dermatologic Ur- 
gencies and Emergencies: What Every Pathologist Should Know. Arch Pathol Lab Med. 2019;143(8): 919-942. doi:10.5858/arpa.2018-0239-ra

13. Blyth M., Estela C., Young AE. Severe staphylococcal scalded skin syndrome in children. Burns. 2008; 34(1): 98-103

14. Grama, A., Mărginean, O., Melit,, L., \& Georgescu, A. Staphylococcal Scalded Skin Syndrome in Child. A Case Report and a Review from Literature. The Journal of Critical Care Medicine. 2016; 2(4), 192-197. doi: https://doi.org/10.1515/ jccm-2016-0028

15. Greendwood J., Dunn K., Davenport P. Experience with severe extensive blistering skin disease in a pediatric burn unit. Burns. 2000; 26:8287

16. David W. Kimberlin, Michael T. Brady, Mary Anne Jackson, Sarah S. Long. Red Book Report of the Comittee of Infectous Diseases. 31 ed. Tasca IL: American Academy of Pediatrics; 2018.

17. Arora P., Kalra V., Rane S,. McGrath E., Zegarra-Linares R., Chawla S. Staphyloccocal scalded skin syndrome in a preterm newborn presenting within first $24 \mathrm{~h}$ of life. BMJ Case Report; 2011:bcr0820114733

18. Braunstein I., Wanat K., Abuabara K., McGowan K., Yan A., Treat J. Antibiotic sensitivity and resistance patterns in pediatric staphylococcal scalded skin syndrome. Pediatrics Dermatology. 2014; 31:305-8

19. Patel G, Finlay A. Staphylococcal scalded skin syndrome: diagnosis and management. American Journal of Clinical Dermatology 2003: 4:165-75.

20. Schmidt H., Lissner R., Struff W., Thamm O., Karch H. Antibody reactivity of a standardi- zed human serum protein solution against a spectrum of microbial pathogens and toxins: comparison with fresh frozen plasma. Ther Apher. 2002; 6(2):145-153.

21. Tenendbaum T, Hoehn T., Hadzik B et al. Exchange transfusion in a pre-term infant with hyperbilirubinemia, staphylococcal scalded skin syndrome (SSSS) and sepsis. Eur J Pediatr;2007;166:733-735.

22. Doudoulakakis A., Spiliopoulou I., Spyridis N., Giormezis N., Kopsidas J., Militsopoulou M., et al. Emergence of a Staphylococcus aureus clone resistant to muripocin and fusidic acid carrying exotoxin genes and causing mainly skin infections. J Clin Microbiol; 2017; 55: 2529-37

23. Silversides, J. A., Lappin, E., \& Ferguson, A. J. Staphylococcal Toxic Shock Syndrome : Mechanisms and Management. Curr Infect Dis Rep. 2010; 12(5): 392-400. doi:10.1007/s11908-0100119-y

24. Figueroa-tarrillo, J. A., Cerna-viacava, R., \& Linares-linares, M. A. Síndrome de shock tóxico fulminante: reporte de un caso. Revista Mexicana de Pediatría. 2015; 82(6): 200-203.

25. García, C. A., Luna, Z. M., \& Acosta, J. G. (2015). Síndrome de Shock Tóxico en el Puerperio. Reporte de un caso. Revista Chilena de Medicina Intensiva. 2015; 30(2), 87-91.

26. Fakoya AOJ, Omenyi P, Anthony P, Anthony F, Etti P, Otohinoyi DA, Olunu E. Stevens - Johnson Syndrome and Toxic Epidermal Necrolysis ; Extensive Review of Reports of Drug-Induced Etiologies, and Possible Therapeutic Modalities. Open Access Maced J Med Sci. 2018; 6(4): 730738.

27. Mockenhaupt, M. Stevens-Johnson syndrome and toxic epidermal necrolysis: clinical patterns, diagnostic considerations, etiology, and therapeu- 
tic management. Semin Cutan Med Surg. 2014; in pemphigus foliaceus and vulgaris. J Clin Invest. 33(1):10-16. https://doi.org/10.12788/j.sder.0058 1999; 103: 461-8.

28. Torres, M., \& Olmos, E. Reacciones medicamentosas severas. Síndrome Stevens Johnson y síndrome DRESS. Acta Médica Colombiana.2013; 38(2): 76-82.

29. Corneli, H. M. DRESS Syndrome. Pediatric Emergency Care.2017; 33(7): 499-502. doi:10.1097/pec.0000000000001188

30. Husain, Z., Reddy, B. Y., \& Schwartz, R. A. DRESS syndrome. Journal of the American Academy of Dermatology. 2013; 68(5), 693.e1-693. e14. doi:10.1016/j.jaad.2013.01.033

31. Mahoney M., Wang Z., Rothenberer K., Koch P., Amagai M., Stanley J. Explanation for the clinical and microscopic localization of lesions
32. Amagi M., Matsuyosih N., Wang Z., Andl C., Stanley J. Toxin in bullous impetigo and staphylococcal scalded skin syndrome targets desmoglein 1. Nat Med. 2000; 6(11): 1275-7.

33. Ladhani S., Robbie S., Garrat R., et al. Development and evaluation of detection systems for staphylococcal exfoliative toxin A responsible for scalded skin syndrome. J Clin Microbiol. 2001; 39: 2050-2054.

34. Mishra, AK, Yadav, P., y Mishra, A. Una revisión sistémica sobre el síndrome de la piel escaldada por estafilococos (SSSS): una enfermedad rara y crítica de los neonatos. The Open Microbiology Journal. 2016; 10(1): 150-159. 